\title{
Differences and Inequalities in Civic Participation among Bulgarian Youth
}

\author{
Siyka Kovacheva ${ }^{1, *}$, Stanimir Kabaivanov ${ }^{2}$ \\ ${ }^{1}$ Department of Applied Sociology, Faculty of Philosophy and History, University of Plovdiv, Bulgaria \\ ${ }^{2}$ Department of Finance, Faculty of Economic and Social Sciences, University of Plovdiv, Bulgaria
}

Copyright $\bigcirc 2016$ by authors, all rights reserved. Authors agree that this article remains permanently open access under the terms of the Creative Commons Attribution License 4.0 International License

\begin{abstract}
This paper addresses the question: what explains the differences in young Bulgarians' involvement in informal volunteering, participation in associations and civic protests twenty-five years after the regime change. The explanation is based on the results of a representative social survey with 1030 young people aged 14-27 in the summer of 2014, funded by the Friedrich Ebert Foundation. The data show that both attitudinal and behavioral measures of civic engagement are influenced, albeit in different degrees, by structural factors such as gender, education, family background, ethnicity, locality and socio-economic status. A very important intervening variable is trust which in this survey is measured towards a variety of social groups. In general, young people in the country tend to express high trust in family and friends and low trust in people outside their immediate milieu. This kind of social capital mobilizing closed horizontal ties ensures support in uncertain times but does not enable more enriching, even if uncertain, contacts with members of wider communities. It also influences the types of voluntary actions young people engage in: more often informal personal assistance for people they know or see directly and much less often formal involvement in NGO activities. Having higher education, middle to high socioeconomic status, living in large cities or the country's capital provide opportunities for the young to recognize the benefits of membership in civic associations.
\end{abstract}

Keywords Youth Participation, Voting, Volunteering, Civic Values, Trust, Social Inequalities

\section{Introduction}

Youth participation has attracted a growing research attention over the years, which has been fed by recurring outbursts of youth mobilizations, as well as by the seeming absence of civic involvement in the more peaceful periods between protests. Normative assumptions about the 'proper' forms and demands of youth movements and policy concerns with the 'civics deficit' have brought about a proliferation of studies of youth involvement in public life. It is assumed that active participation is a route to young people's integration in society and social cohesion more broadly. Youth engagement in the democratic institutions serves to legitimate policy decision-making in the youth field by claiming that young people's voice is heard and represented in policy programs and measures. Policy makers tend to define participation as involvement only in officially recognized and formalized channels [1] [2] and overlook informal everyday participatory practices of young people.

In classical political science mass participation is put forward as a prerequisite of democracy [3] [4]. Much of the more recent research [5] [6] is built upon rational choice theories with the aim to create models explaining age and other differences in both conventional and unconventional political engagement.

Youth studies provide a more nuanced picture of youth involvement in public life by expanding the research field in several significant ways. First of all, youth research has explored non-traditional and non-formal ways in which young people are engaged in civic and political life [7]. We now have accounts of myriad intangible participatory practices beyond the institutional/non-institutional divide. Second, and linked to this, youth studies have widened the meaning of participation beyond the traditional understanding of the political as a power to influence broader communities. Research reveals how civic participation is closely linked to young people's identity formation and personal self-realization [8] [1]. Young women and men are searching for new styles of participation that are more flexible in meeting their individualized concerns and which allow the linking of subjective biographies with public issues [2] [9].

Underlining the significance of youth participation might lead to 'romanticizing the relationship to social change', as Miles [10] warns against. In late modern consumer societies young people's experience is 'more about reproducing everyday patterns of consumption than it is about challenging those patterns' $([10], 106)$. The trend to 
overestimate youth contribution as actors of social change is present in studies which tend to homogenize young people. However, a third important input of youth studies is bringing to light the social inequalities in the resources of participation. Different forms of participation reflect old and new patterns of inequalities and young people in vulnerable situations face more barriers in their participatory practices than those with wider access to social resources [11].

While examining the complex array of meanings which young people attach to their participation would require in-depth qualitative studies, survey data allow capturing the impact of significant social inequalities on participation among young people. This paper is an attempt to explore the forms of participation of young people in a specific social context - post-communist Bulgaria 25 years after the start of the democratic transformation, and on this basis to measure the impact of different social factors hoping to find more meaningful explanations of the forms of youth participation.

\section{Acknowledging the Multiplicity of Youth Participatory Practices}

Large scale surveys tend to register a growing apathy towards politics among the young cohorts in developed societies. Commonly used quantitative indicators such as the frequency of following political news in the media, viewing politics as distant to youth lives, lack of trust and political cynicism have measured high rates of political disaffection among youth in Europe both West and East [12] [13]. However, evidence is not conclusive and other surveys and studies using mixed methods and interdisciplinary approaches have shown that a widening variety of issues attract young people's attention and action.

There are several trends that continue to shape youth political participation in the past few decades and which need more refined inquiry approaches. The high levels of precarious employment and unemployment are not stimulating mass youth membership in trade unions and the declining trust in political institutions is associated with a declining identification with one political party [11] [14]. On their side many political parties and trade unions demonstrate diminishing interest toward young people and have started to invest less in their youth sections thus loosing an effective channel for recruitment and political education [15]. Among youth there is a re-orientation toward single issue politics, the so called 'politics of choice' [16] [17], instead of holding a consistent ideological orientation.

This trend is linked to the orientation of young people toward more individualized forms of political participation such as political consumerism [18] [19]. Another expression of this cultural shift is the inclination of the young to participate in more self-expressive forms of involvement attempting to influence political, economic and social practices and to give political meaning to participation in cultural and sports scenes. Studies have shown youth inclination to identify leisure as a form of resistance to the neoliberal positions [20].

Young people were in the forefront of the cultural changes toward post-materialistic values [21] which resulted in their massive involvement in non-institutional politics. Protest politics is appealing to the young with the opportunities for direct, less formalized and less hierarchical actions. The old social movements which arose in the industrial societies were class based, addressing state power and raising materialist goals. In contrast, the new social movements are post-industrial, have a wider range of social group representation, address civil society and express claims to autonomy and free public spaces. The latest cycle of collective action which started as an anti-corporate or alter-globalization movement is characterized with a new culture of commitment and identity based demands, transnational networks, the use of new communication technologies and innovative forms of action with a symbolic emphasis [22] [23].

The movements protesting globalization are not youth movements per se and young people are only one group among their forerunners. A truly youth wave of mass action in European societies in the $21^{\text {st }}$ century were the spring 2011 protests in Spain, Portugal and Greece that addressed topical social problems such as the sweeping unemployment for the young generation, the welfare cuts in education, health and social protection. Having different names such as the $15-M$, 12 March, and Direct Democracy Now!, the movements also came to be known by the name of the Indignados for their strong rejection of the current governmental solutions to the crisis, against corrupt politicians and bankers.

Elsewhere in the world youth protests also challenged the thesis about youth estrangement from politics. The civil disobedience against the proposed reform in Hong Kong's electoral system in the autumn of 2014 was initiated and led by students. The protestors claimed inspiration from the 'Arab Spring' - the 2011 revolutions in Tunisia, Egypt and other North African countries, as well as with earlier youth protests such as the student demonstrations in the UK in 2011, Greece in 2008 and France in 2006 which in turn triggered comparisons in the media with the 1974 'Carnation Revolution' in Portugal and the 1968 occupations of the Sorbonne in Paris. Similar historical links were sought after by young people participating in the 'color revolutions' in Ukraine, Georgia and other former Soviet republics in 2004-6, where the identity frames of the movements stressed the commonalities in goals and forms of action with the 'gentle revolutions' in 1989-91 and the upheavals in 1997 in Central and Eastern Europe [24] [25].

Discussing present day youth participation, several pressing questions seem to need answers. How have the new economic and political opportunities and constraints influenced the propensity of the young to get involved in public life? What are the influences of the latest shifts in young people's values on their styles of participation? Surveys have measured differences in the interest toward politics, views about personal efficacy, satisfaction with and membership in parties and other political organizations, 
voting and protest activities between the group of unemployed young people and those in education and in work ( [27], [28]). Gender differences in political involvement have been much debated as well as examined empirically although results have often been mixed and inconsistent [29]. One factor with growing significance for social inequalities among youth is family background. The lack of access to jobs and the prolongation of studies, the housing market crisis and rising student taxes make young people more dependent on their parents. The intergenerational transfer of wealth, emotional and practical support help to alleviate the high costs of youth unemployment, but it also acts as a mechanism for rising social inequality because there is an intergenerational transmission of poverty and insecurity. Social research has encountered a correlation between social disadvantage and higher acceptance of violence in demonstrations as the only way to influence decision-makers ([11]: 79). Another explanatory factor has been sought in the influence of religion on the forms and contents of young people's non-institutional political participation. There is evidence that religion is seen as offering solutions to social problems in the Middle East and North Africa and is high on the agenda of youth protests there. Within religious communities there is significant differentiation in the tolerance towards violence [26]. What is more, we can expect that similar trends might have a diverse impact on youth engagement in different national contexts.

\section{The Social Context of Youth Participation in Bulgaria}

The pluralization of the forms and contents of youth participation in late modern societies did not leave aside young people in Bulgaria whom we studied in 2014. In order to understand the specificity of their involvement in public life we have to look deeper into the social situation in the country twenty-five years after the regime change in November 1989 and seven years after the EU accession. The events of 'the Gentle Revolution' in 1989 in Central and Eastern Europe which confronted their parents' generation are beyond the personal experience of today's youth and they can learn about it only from books or their parents' stories. For young Bulgarians the market economy and the democratic political system are taken for granted which they rarely think about in terms of gains and losses, unlike the older generations [30].

The social and economic situation for young people is shaped by the consequences of the 2008 global financial crisis and the slow recovery of the country's economy. At the same time neither economic output nor employment contracted so sharply as in other Southern European countries such as Greece and Spain. The political instability in 2013 and 2014 is also part of the context of youth participation. In the winter of 2013 mass demonstrations against the 'oligarchs' led to the resignation of the center-right government and early elections. The newly formed center-left government did not enjoy a long period of peaceful governance and faced a new protest mobilization in the summer of the same year, this time directed against backroom politics. The waves of discontent continued till the elections for the European Parliament in May 2014 after which the government resigned and early elections were called yet again. The protests which led to two consecutive governmental changes were accompanied by much weaker youth participation than during the student 'occupations' of university buildings in 1990 [31] or the 'jumping marches' in the streets in 1997 [8]. Also, in the two previous protest waves there was a clearer generational divide with young people in favor of the social change; in the latest one young people were present in both campaigns - both 'for' and 'against' the current government in office.

The official statistical data since 1989 indicate a tendency towards a decrease in the relative demographic weight of those aged $15-29$ (currently at $17 \%$ of the total population) and the prognosis of the National Statistical Institute is that this trend will continue at least until 2020. This comes as an obvious result of the falling birth rate and the continuing emigration abroad that is still significantly higher than the immigration flow. Behind these processes however are the problems in the social integration of young people and above all the vulnerable situation of youth in the labor market.

Eurostat (2014) places Bulgarian youth in the group of young people who begin looking for a first job late, most often after completing their studies, and who rarely combine studies with work. This group includes youth from many East European countries, such as Croatia, the Czech Republic, Hungary, Romania and Slovakia. Those countries are characterized by a labor market with few flexible forms of employment such as part-time or casual jobs. Bulgarian youth transitions are very different from those in the Nordic countries, the Netherlands, the United Kingdom and, to some extent, Slovenia, where there is a significant overlap between education and employment because of the tradition for students to work in part-time or summer jobs. They also differ from youth pathways in Germany and Austria countries that have established apprenticeship systems or vocational training in secondary education, which allow a significant part of young people to work for pay during their studies.

A detailed look at the domains of work and education reveal other specific features of the social situation of Bulgarian youth today. Despite the mass expansion of higher education in the first years of the transition in Bulgaria, when a number of new private institutions began offering education services and older state universities opened branches across the country, the share of young people with tertiary education attainment still remains below the average for the European Union (EU). In the group of young adults (30-34 years), the people with tertiary education attainment in Bulgaria are $29.4 \%$, as compared with an average of $36.9 \%$ for the European Union. In Bulgaria, the share of young women with tertiary 
education attainment significantly exceeds that of young men $-37.6 \%$ for women and just $21.8 \%$ for men [32].

Regarding the lower educational level, Bulgarian youth's access to secondary education is comparatively high and is above the share in the EU as a whole. Early leavers from education and training in Bulgaria are still a significant group among youth, reaching $12 \%$, although there is a positive downward trend. On this indicator Bulgaria occupies a middle position, very close to the average for the EU and between the lowest shares of $3.7 \%$ in Croatia and $5.4 \%$ in the Czech Republic and the highest 23\% in Spain. The young people who leave school early in Bulgaria come predominantly from rural areas and small towns and from ethnic minorities. Primary schools in Bulgarian cities are still segregated along ethnic lines [33] although in villages they are mixed due to the low number of children in rural areas. There are state programs and civic initiatives for de-segregation without much success.

Early leavers from education and training are at twice the risk of failing to enter the labor market. Whereas the youth unemployment rate for the 15-29 age group in Bulgaria in 2014 was $21.8 \%$ [34], it was as high as $44.8 \%$ among young people with primary education or less (levels 0 -2 according to the European standard classification system ISCED11). The unemployment rate was slightly higher among young men, $22.3 \%$, than among young women $21 \%$. Bulgaria is above the average EU unemployment rate, which represents unemployed youth as a percentage of the youth labor force, and slightly below the average on the "unemployment ratio" indicator which represents unemployed youth as a percentage of the total population of the 15-29 age group. The lower value of the second indicator comes from the lower level of economic activity of Bulgarian youth, especially among the younger groups, those aged 15-19 and 20-24. Another characteristic feature of the situation in Bulgaria is the high level of long-term youth unemployment, reaching a rate of $8.1 \%$.

Indicative of the economic situation of Bulgarian youth are two other statistical indicators: the relative shares of self-employed youth, and of young people not in employment, education or training (NEET). By the first indicator Bulgaria is below the average for the EU, but by the second it is among the countries with the highest shares. The low opportunities for entrepreneurship among Bulgarian youth are linked to the dire state of the Bulgarian economy, the unfavorable legal regulations of business start-ups, a lack of social and political incentives for economic enterprise for the young, and not least, the underdevelopment of educational programs in this area [35]. The NEET group is very heterogeneous but, as a whole, it attests to a status where young people are at a high risk of social exclusion. In addition to the economic costs, it has serious social consequences for the other youth transitions to an own home, partnership and political participation.

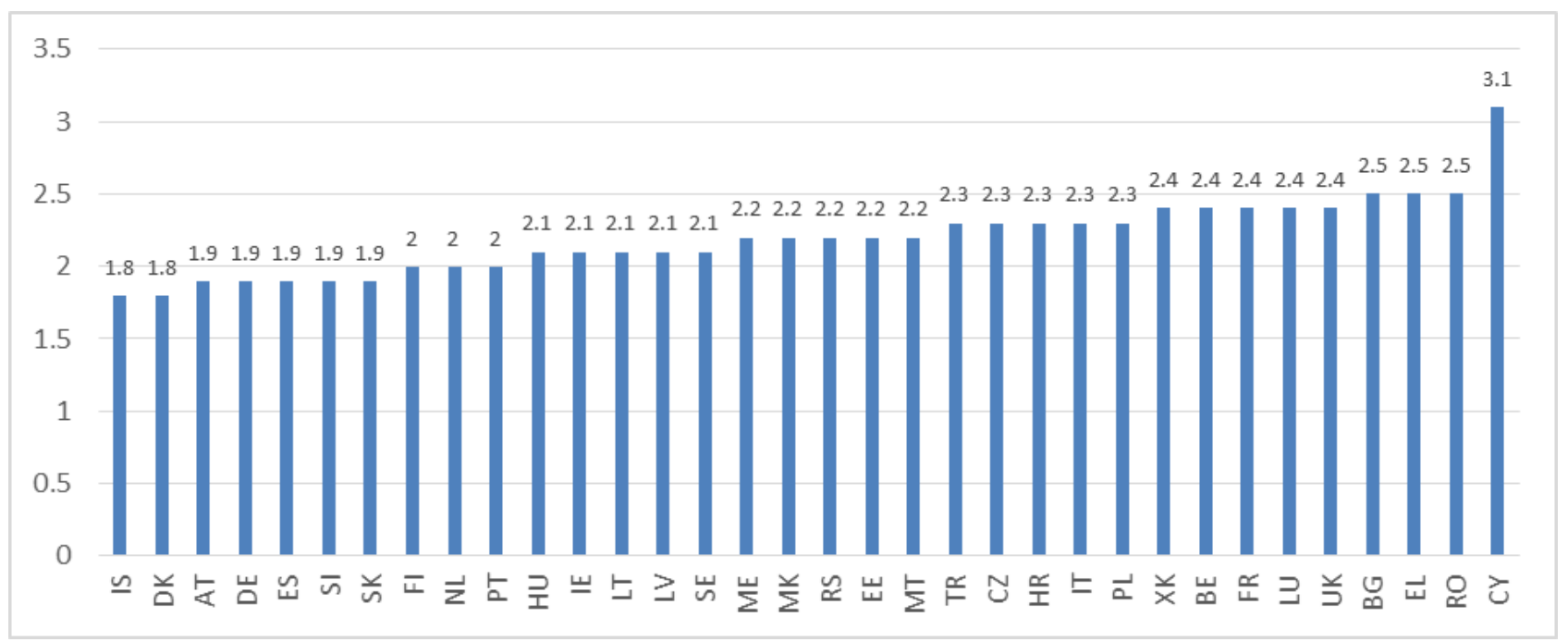

Source: http://www.eurofound.europa.eu/surveys/data-visualisation/european-quality-of-life-survey-2012

Figure 1. Perceived social exclusion index per country for young people (aged 18-24) 
Many of the indicators used by Eurostat to measure poverty and social exclusion depict a bleak picture of youth conditions in the country. Thus Bulgaria has the highest share of young people with an equivalized disposable income below $60 \%$ of the national equivalized median income - above that in Romania and Greece. Eurostat [32] has also found one of the highest levels of material deprivation among Bulgarian youth in satisfying basic needs such as food, heating, and household items. Experiencing this situation as social exclusion is a realistic threat for young people in the country. The perceived Social Exclusion Index of the European Foundation for the Improvement of Working and Living Conditions ${ }^{1}$ indicates that after Cyprus, social exclusion was highest in Bulgaria, Romania and Greece (Figure 1.). Insofar as social exclusion is a much more diverse phenomenon than material deprivation, this seems a more appropriate indicator.

Compared with the standard of living of their peers in other EU countries young Bulgarians are at a disadvantage. Within the group inside the country, however, social inequalities are no less significant. A major divide exists between the privileged minority of the 'golden youth' and the underprivileged majority of young people at risk. Bulgaria quickly moved from a rather equal society in terms of income to a highly unequal one and in 2014 had a Gini coefficient (of equivilized disposal income) of 35.4 - well above not only the Gini coefficients 25 and 25,1 respectively in the former socialist countries such as Slovenia and the Czech Republic, but also the EU average of 30.9. Family background has become even more important than during communism in transmitting economic, social and cultural capital [30]. While immigrant youth is still in a very small proportion of the population tending to stay temporarily before moving West, ethnic inequality among traditional groups remains very high with the Roma being most deprived in terms of access to education, employment and housing. Geographical disadvantages are most pronounced between rural and urban areas. Young people with physical and mental disabilities face more barriers in their integration at school and work. Stereotypes about gender roles, particularly within the family, prevent women from achieving career success equal to that of men. The new communication technologies impact youth condition in contradictory ways: the spread of computers and home Internet access work towards greater equality while laptop and smart phone use create a clear divide among richer and poorer households.

The question remains: how do these inequalities as well as similarities among young men and women in the country affect their civic mindedness and their practices of civic participation?

\section{Data and Methodology}

In search of an answer to this question we did secondary

1 http://doc.ukdataservice.ac.uk/doc/7724/mrdoc/pdf/7724 eqls userguide. pdf analysis of the data set from the Bulgarian Youth Study [30]. It was carried out in the summer of 2014 as part of the Friedrich Ebert Foundation's research project on youth in the Balkan countries based on a common questionnaire developed in 2005 for Germany's Shell Youth Studies [36]. The methodology of the study in Bulgaria combined a face-to-face survey with 1030 respondents aged 14-27 and 10 in-depth interviews with young men and women in different social situations. The representative survey used a two-stage cluster sample (206 clusters) stratified by region (28 regions) and type of settlement (capital city, regional center, small town, and village) based on a systematic random sample of polling districts in Bulgaria. The data were processed using SPSS and hypotheses were tested by chi-square, t-test, and analysis of variance. The purposive sample of 10 cases for the qualitative study aimed at an equal distribution of interviewees by gender and age (14-20 and 21-27 years). We aimed at a maximum diversity of occupational statuses and those selected were pupils at high schools, university students, employed and unemployed youth. With the expectations that ethnic differences have a significant impact on young people's orientations, interviews were conducted with six ethnic Bulgarians, two ethnic Turks, and two Roma. The interviews lasted for an hour or an hour and a half and were recorded with the respondents' consent and then fully transcribed. The data set was first analyzed and presented in a book describing the attitudes and forms of behavior of young people in the country seven years after it became a member of the EU [30]. In this paper we turn again to the same empirical data with the objective to do a more-in-depth analysis of one particular field of young people's activities - participation in public life.

The research instrument covered the attitudes and experiences of young Bulgarians in a wide range of life domains: family, school, work, leisure and politics. It provided rich data on the values and behaviors of young men and women in order to understand their life choices. The comparison with previous studies of the country's youth in the 1990s showed a growing pragmatism of the new generation with a preference for jobs in the private sector, distancing from partisan political conflicts, diversified forms of family arrangements and a growing significance of consumption in the process of identity formation [30]. The findings of the study also attest to the continuing trend of individualization of the young for whom the first choice of values is now 'freedom' which is manifested not only in the multiplicity of leisure pursuits but also in educational and work preferences and, most significantly, in relations with parents. The character of family communication is changing allowing a greater autonomy for the young - for their life styles even when still living in the parental home, for the choice of a partner and a form of partnership, for political views which are now discussed more openly with parents (to replace the former absence of dialogue). What now plays a restrictive role for achieving autonomy by the young is not the paternalism of the socialist state typical for the situation before 1989 but the economic status of the family where 
poverty increases dependence on parents for educational prospects and transition to work [30].

For the analysis of this paper we first considered descriptive results from the measures of youth participation and civic mindedness. We then created a model of youth participation building on the available behavioral and attitudinal measures and socio-economic indicators of youth transitions. We tried to find the most common forms of civic involvement as well as whether those young women and men who were active in one form were also active in other forms, and if there was a difference among the different groups, whether this was due to some forms of social inequality or whether it was an expression of life style preferences.

The survey provided data on the following forms of youth participation:

- Participation in elections

- Involvement in violent conflicts

- Participation in voluntary activities

- Membership in non-profit organizations

Voting is a form of political involvement which is interpreted as institutional participation and is usually combined with other activities such as working for a party regularly or in an election campaign, making donations for a party or contacting politicians. Participation in a violent protest on its turn is construed as non-institutional or unconventional participation. Those two forms have political character as they challenge state or party politics. We also understand them as civic activities because electoral participation is not obligatory in Bulgaria and is considered a form of civic duty. The other two styles - the more informal involvement in various types of voluntary activities and the more formal engagement of being a member of non-governmental organizations - are civic activities per se.

\section{Descriptive Results}

The political situation in the country at the time of the survey was influenced by one of the most serious political crisis after the regime change in 1989. In the two years preceding the survey there were two early elections called after mass protests and in May 2014 the elections for the European parliament were held. The survey was conducted one month later - in June in a situation of popular expectations for change. The quantitative data from the youth survey revealed that a third of the young respondents had voted in all elections for which they were eligible and nearly half had taken part in some of the elections. About one in ten of the young had been involved in physical conflicts in the neighborhood where they lived, or at school and, more rarely, at sports events and protest demonstrations in the past 12 months. There were different reasons mentioned as a trigger of a physical fighting in the study. Regardless of the exact reason we consider that it represented a rather extreme, yet very strong, form of personal involvement.

The survey results were indicative of the difficulties in overcoming the political instability in the country. Interest in local, national, European and world politics varied between a quarter to a third of the respondents and trust in national political institutions was expressed by only one fifth of respondents. Mistrust was highest towards the parliament, government, political parties and trade unions - the main institutions that make a democracy work. The young respondents trusted European institutions better and the most trusted institution in the list of 15 institutions was the European Court of Justice. Dissatisfaction with the state of democracy in the country was widespread among both right-wing and left-wing oriented respondents. Democracy was valued as ideal systems as was the market economy but the young were highly critical of the way it was functioning in the country. The European Union was perceived as a better guarantee of justice than the national institutions and synonymous with 'travel' and 'employment'. From the list of ten European values, the young ranked first 'freedom', followed by 'democracy' and 'market economy'.

In the interviews young people explained their dislike towards personal involvement in politics which they viewed as party scuffles that were far away from young people's lives. A Roma man who combined studies with a part-time job justified his view in the following statement:

Political life is lived by the politicians, it's best for them. While they are at some high level, we, the other people, are down below... They throw us the crumbs, they don't give us a chance, and they won't help us even a little. There's nothing, no development at all...

A student in one of the most prestigious majors at university - informatics - argued for individual solutions outside politics:

Politics ...doesn't make a particular difference for my way of life. Whether it will be one [political] party or another [doesn't make any difference]. I don't rely on a concrete party to save us or to fix life. It can't. I rely on myself and to some extent on the fact that we are in the $E U$.

Even youth participation in mass protests was seen by many as a rewarded rather than spontaneous expression of young people's discontent. An 18-year old woman at a Sofia high school maintained that:

...most young people from my circle aren't interested [in politics]. Otherwise, at the time of the protests, many people I knew took part in them. Some went [to the protests] to earn the money for their seaside holiday. It was an absolute parody.

In the mass media throughout 2014 there were often accusations that participants in the demonstrations for and against the Socialist government currently in office were being paid for their activities. Such claims were never proven but were regularly used in the public debates by political opponents. The lack of trust towards political institutions had spread over to the non-institutionalized forms of political participation. 
When these more politically oriented forms of youth participation did not appeal strongly to young Bulgarians, they did not turn in greater numbers to the other two forms: membership in non-profit organizations and doing voluntary work. In the questionnaire participation in voluntary activities was defined as "unpaid work done voluntarily over the last 12 months". Despite this broad definition only one quarter of the respondents reported engagement in this type of civic participation. Among the listed activities most common were public works in the local community, peer help with studying, and assistance of mobility-challenged people. Much rarer was the practice of voluntary participation in organizing cultural and sport events, religious based charity or donating money to nongovernmental organizations. The results suggest that Bulgarian youth were more inclined to assist people they personally knew (neighbors and schoolmates) or saw directly (mobility-challenged people in the street), and were much less likely to participate in organized civic activities.

The other form of civic engagement that we included in the model was membership in organizations. This more formal style of participation was very low among young men and women in Bulgaria. Just $15 \%$ of the respondents were members of some registered organization. Half of these participated in sports clubs. Youth associations, including pupil and student councils, accounted for slightly over 5\% of the respondents. This $15 \%$ 'membership' rate measured in 2014 is a certain increase compared with the five-percent share recorded in 2002 [37]. Yet even so, youth formal participation has not reached a "healthier" level of association that will allow young people to raise and seek to resolve social issues in a democratic society.

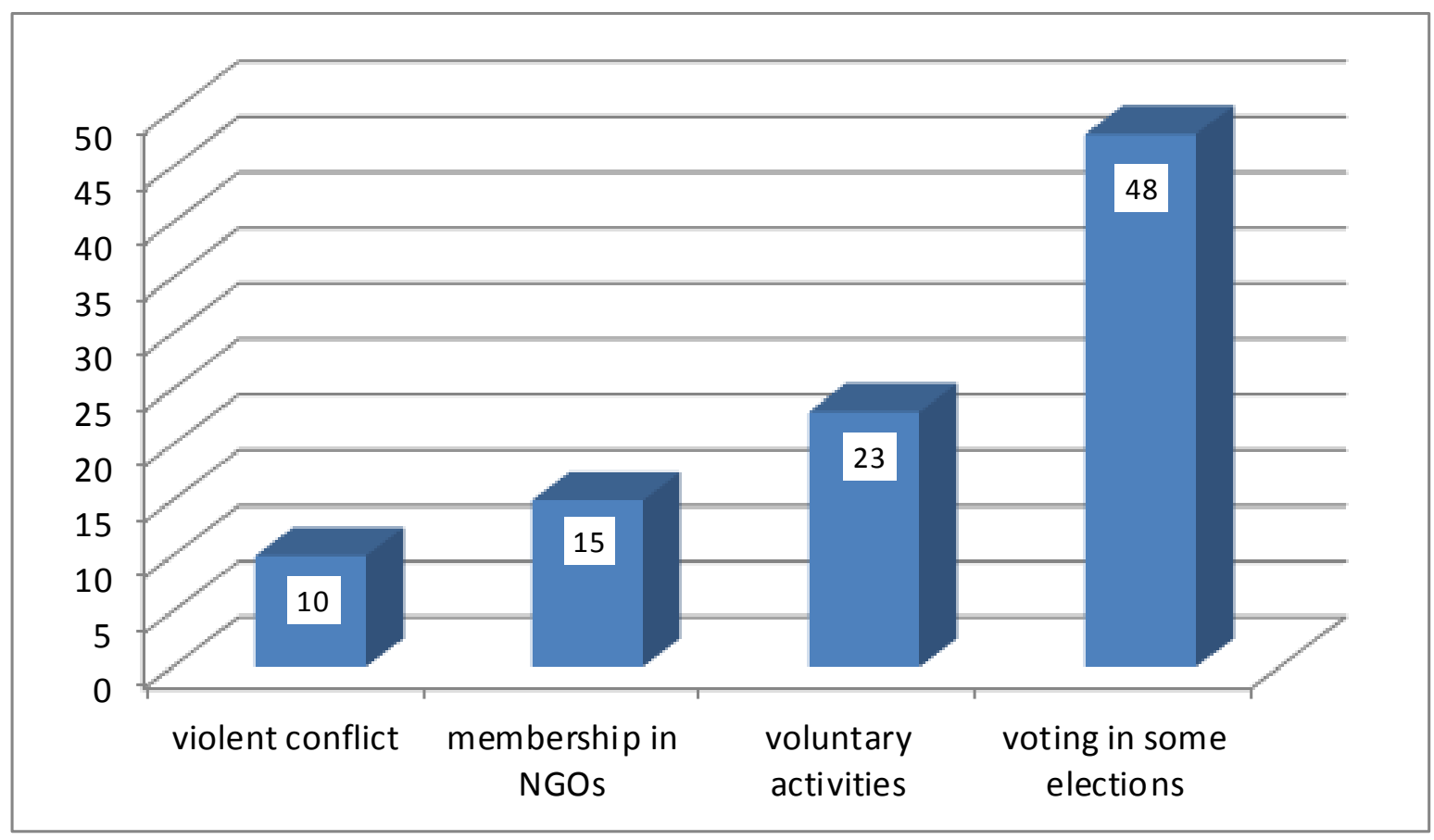

Source: Bulgarian Youth Survey 2014 data base.

Figure 2. Forms of youth participation (\%) 
The survey provided data on various aspects of young people's civic mindedness. Civic mindedness was measured by variables such as whether respondents considered being active in politics and in civic initiatives to be 'in' or fashionable (among a list of 13 activities), whether they were interested in local, national or world politics; and whether they could define their attitudes on the left-right spectrum. We paid a special attention to the value of 'trust' which has been proved in many studies [38] [39] to be conducive to democratic participation. In our study trust was measured both at the interpersonal and at the institutional level and the results corroborated previous findings about the low levels of trust expressed by Bulgarian respondents [40]. There was one significant specific characteristic which deserves mentioning. The indicator we used did not measure abstract interpersonal trust (towards other people in general) but trust in specific social groups, such as parents, neighbors, friends, and people with different political and religious views. The top three most trusted groups were parents, siblings and friends. The levels of trust in neighbors and colleagues (from work/school/university) were significantly lower, while trust in people of other religions was higher than in people with different political persuasions. We interpreted this finding as an inclination towards creating horizontal ties and investing in 'binding' form of social capital - a form that ensures support in uncertain times but does not enable wider and more enriching, even if uncertain, contacts with other social groups. The inability to extend one's trust from the immediate social milieu to more anonymized and supra-individual relations might be a major obstacle to their civic participation.

The qualitative interviews corroborated the observation that Bulgarian youth did not recognize the importance of the 'bridging' form of social capital. It seems that the relations of trust and reciprocity among individuals with different social statuses had not yet become an area for social investments. Young people still saw social capital mostly in its negative aspect, as a basis for nepotism - the practice of giving plum jobs to friends or relatives regardless of their personal qualities. This widespread conviction among interviewed young people was summed up by a 17-year-old pupil in a high school specializing in mathematics:

You need to have connections, or, if you have rich parents, you've already made it in life.

Similarly, an economics major claimed:

In Bulgaria, unfortunately, you can't achieve anything by just working hard. You have to be dishonest to succeed in life. (...) You need to have connections and to know quite a few people, at that, in high places - I mean directors, politicians, [someone] at a much higher level than mine who will make sure I get a job at his company.

Young people's narratives provided abundant evidence of the association they made between distrust in political institutions, politicians, routes to success in education and work, and their disinclination to get involved in public activities. In order to measure whether this link is statistically significant used the survey data to create a regression model for the factors influencing the different forms of youth participation.

\section{Explaining Youth Participation}

We studied the four main forms of participation as dependent variables in our model and then tried to explain them by examining the impact of several independent variables. Our main hypothesis was that general youth participation could be presented by these four forms and that motivation driving it could be explained through studying a finite set of factors including socio-demographic characteristics of the participants as well as their attitudes to and perceptions of institutions. In order to test our main hypothesis, we took two steps - first we defined the groups of independent variables that we expected to drive youth participation, and second we created regression models with four different dependent variables, each representing a separate participation form. Using different regression models is necessary in order to verify if the same factors remain statistically important across different participation forms as well as to test if the explanatory power of the selected independent variables is similar across different participation forms.

The first group of independent variables consisted of socio-demographic controls such as gender, age, completed education and current occupational status. We also included some indicators linked to the family situation of the young people: parents' education, household socio-economic status, size of household expenditures, and place of living. We hypothesized that young people's ethnicity and religious affiliation would also influence their civic behavior and included these in the model. Another major group of explanatory variables was the civic mindedness of young people as measured by the attitudes to politics, trust in institutions and social groups, experiences of discrimination and European values linked to democracy, solidarity, competitiveness, freedom and market orientation.

Multiple logistic regressions were conducted with the objective to examine the influence of various factors on four models, each one with a dependent variable related to: participation in voluntary activities, participation in formal organizations, voting participation and as an extreme part of involvement - participation in a violent conflict. This type of regression analysis was chosen because of its ability to model dichotomous output, and the use of probability concepts when interpreting the results. We have decided to analyze different forms of participation separately since they include different types of involvement - for example membership in civic organization suggests more formal relations. Therefore, constructing a single index of participation would also require assigning different weights of all included forms of participation which is beyond the scope of our study. 
Table 1. Models of Youth Participation

\begin{tabular}{|c|c|c|c|c|}
\hline Model/Factor & $\begin{array}{l}\text { Voluntary } \\
\text { activities }\end{array}$ & $\begin{array}{l}\text { Membership in } \\
\text { civic organization }\end{array}$ & $\begin{array}{c}\text { Voting } \\
\text { participation }\end{array}$ & $\begin{array}{l}\text { Involvement in } \\
\text { violent conflict }\end{array}$ \\
\hline-2 Log likelihood & 450,475 & 359,471 & 314,164 & 341,467 \\
\hline Cox \& Snell R Square & 0,307 & 0,251 & 0,450 & 0,316 \\
\hline \multirow[t]{2}{*}{ Nagelkerke R Square } & 0,431 & 0,409 & 0,601 & 0,498 \\
\hline & $\beta$ & $\beta$ & $\beta$ & $\beta$ \\
\hline Age (ref. 18-22) & $-0,744 *$ & & & \\
\hline Gender (ref. woman) & & & & $-1,774 * * *$ \\
\hline Respondent's completed education (ref. below high school) & & & & $2.931 *$ \\
\hline \multicolumn{5}{|l|}{ Respondent's occupational status } \\
\hline (ref. employed) & $1,142 * *$ & & & \\
\hline (ref. studying) & & & & $1.740 * *$ \\
\hline Ethnic group (ref. Roma) & & $-4.130 * *$ & & \\
\hline Religion (ref. Islam) & & & & $-2,621 * *$ \\
\hline \multicolumn{5}{|l|}{ Family socio-economic status } \\
\hline (ref. well to do) & & & & $-3,643 * *$ \\
\hline (ref. below medium) & &, $725^{*}$ & & \\
\hline \multicolumn{5}{|l|}{ Typical monthly household living expenses } \\
\hline Do not want to disclose this information & $-1,158^{*}$ & & & \\
\hline $2001-2500 \mathrm{BGN}$ & & & & $4,204 * *$ \\
\hline $1801-2000 \mathrm{BGN}$ & & & $-2,526 * *$ & \\
\hline 1401-1600 BGN & & $-2,573 *$ & & $1.648^{* *}$ \\
\hline 1201-1400 BGN & & & & $2,035^{* *}$ \\
\hline up to $250 \mathrm{BGN}$ & & $1,381 * *$ & & \\
\hline Place of living (ref. large city) & & &,$- 981 *$ &,$- 825 *$ \\
\hline Living arrangements (ref. with friends) & & & $-6,532 * *$ & \\
\hline \multicolumn{5}{|l|}{ Mother's education } \\
\hline (ref. university) & & & & $-2,310^{*}$ \\
\hline (ref. high school) & & $-2,127 *$ & & \\
\hline \multicolumn{5}{|l|}{ Trust in: } \\
\hline Family members & &, $083 * *$ & &,$- 370 * *$ \\
\hline Relatives & & & &, $111^{*}$ \\
\hline Friends & &,$- 093 *$ & & \\
\hline Neighbors & & & &,$- 110 * *$ \\
\hline Colleagues from work, school, university & & &,$- 024 * *$ & \\
\hline People with different religious affiliation & & & &,$- 015 * *$ \\
\hline People with different religious beliefs & & & &, $009^{*}$ \\
\hline \multicolumn{5}{|l|}{ Trust in: } \\
\hline Bulgarian political parties & &, $568 * * *$ & $-2,726 * * *$ & \\
\hline Bulgarian parliament & &, $479 * *$ & & \\
\hline Bulgarian judiciary & ,263** & - & & \\
\hline Bulgarian orthodox church & & &,$- 347 * * *$ & \\
\hline Local authorities & &, $217 *$ &, $317^{*}$ & \\
\hline European parliament &,$- 314 * *$ &,$- 552 * * *$ & & \\
\hline European Commission &, $208^{* *}$ & - & ,220* & \\
\hline European Court of Justice &,$- 166^{*}$ & ,205* & -.187 & \\
\hline Media & ,207* & - & ,344* & \\
\hline Chief prosecutor & & &,$- 287 * * *$ & \\
\hline Religious leaders & & &,$- 163 * *$ & \\
\hline Trade unions & &, $227 * *$ & & \\
\hline Nongovernmental organizations & &,$- 308 * * *$ & & \\
\hline Satisfaction with democracy in Bulgaria & &,$- 257 * *$ & & \\
\hline Interested in politics (world politics) &,$- 374 *$ & - & &,$- 593 * *$ \\
\hline Interested in politics (Balkan politics) & & &,- 937 &, $722 * *$ \\
\hline Left-right orientation (to the right) & & & & $2,080^{* *}$ \\
\hline \multicolumn{5}{|l|}{ Experience of discrimination on the basis of political beliefs } \\
\hline Often/very often & & & & $2,965 * *$ \\
\hline Rarely & & $2,809^{* *}$ & &,$- 954 *$ \\
\hline Satisfaction with democracy in Bulgaria & &,$- 257 * *$ & & \\
\hline European values (ref. market orientation) & & & $2,489 * * *$ & \\
\hline \multicolumn{5}{|l|}{ Fashionable among youth } \\
\hline (being active in politics) &,$- 137 *$ & - & & \\
\hline (being active in civic initiatives) & $-1,106 * *$ & - & & \\
\hline
\end{tabular}


The results presented in Table 1 reveal that the selected factors explain part of the drivers of youth involvement in civic and political activities. The values of Cox \& Snell R Square vary between 0.25 and 0.45 and those of Nagelkerke R Square - between 0.4 and 0.6 . While these are acceptable explanatory rates in social modeling, we recognize that there are other important factors that have not been included as variables in our study. Although comparison of the goodness of fit that is based solely on R Square is far from being conclusive, our analysis shows that the selected independent variables tend to explain better less formal types of participation, while membership in formal non-governmental organizations is more likely to be influenced significantly by factors that are not included in the model. The explanatory power of the four models corresponds to our hypothesis that selected forms of participation can be explained in a similar way and to a similar extent with proposed regressions. However, it should also be noted that not all factors are valid throughout all analyzed participation forms.

\section{Discussion}

We found several common factors that influenced all examined forms of involvement as well as others that exerted specific impact on some of the forms. Out of the entire explanatory variables monthly household living expenses were consistently significant for all four models built. Respondents with the lowest and the highest levels of monthly income seemed to be less likely to engage in voluntary activities as well as in the voting process ${ }^{2}$. It is worth noting that involvement in a violent conflict was positively related to the increase in monthly income. One possible explanation is that the increase in monthly income allows visiting sports events and night clubs more often and these two cases are major contributors to the involvement in physical conflicts. Respondents with very low living expenses (that also in the common case infers low income) are more likely to participate in different civic organizations, although it is a matter of further analysis whether these organizations are mostly used to provide them with support or membership is driven by reasons beyond financial gains. We paid special attention to the group of respondents who did not just omit answering the question but consciously did not want to disclose the information about their monthly expenses and it could be expected that this was a group hiding their household income from the tax authorities or at least thinking that they were having unusual expenses and did not trust the anonymity of the study). The regression model should that this group was less likely to be involved into voluntary activities. This result deserves a further study of its own.

The analysis reveals that characteristics, such as religion,

2 We should note that the results for the highest income bracket are less reliable (due to having a small number of respondents that fit into this category). gender and employment or unemployment do influence participation and civic involvement, but their importance is rather limited, compared to the other factors in the model. Women are less likely to participate in a violent conflict. The same is valid for young Islamic people. Roma respondents are more likely to take part in civic organizations. It is also worth noting that age seems to have impact on involvement in voluntary activities (with younger respondents clearly participating more in such activities) while they are not statistically significant with regard to voting or physical conflict involvement. Young people with a lower level of education are more likely to get involved in a physical conflict. This is also valid for those who are still at school. People living in smaller towns and villages are also more likely to be politically involved and participate in the voting process. The negative sign of the estimated coefficient here indicates that the larger the place of habitation the less likely it is for the respondents to participate in the voting process. Young people in rural areas are also more likely to get involved into physical conflicts, although examination of the available data shows that reasoning for this conflict also differs. In particular respondents in small cities and villages are more likely to get into physical conflicts with young people in their neighborhood, at a night club or at a sports event, rather than due to political reasons, for example conflicts with the police during demonstrations.

Trust in political parties, the government and the EU institutions have a positive effect for involvement in both voluntary activities and elections. Here the negative sign for the beta coefficients indicate that higher trust contributes to increase in the involvement (categories and trust values are in inverse proportion). As expected, the high mistrust in political parties is correlated significantly with the propensity to vote. It is worth noting that trust in European institutions (in this particular model European Court and European parliament) has approximately the same influence. This means that young people seem to treat different European institutions in a similar way. Also trust in different religious institutions (the Bulgarian Orthodox Church and other religious institutions) seems to have similar impact (supported by the same sign of the coefficients) for the participants in the survey. Young people trusting European institutions to a greater extent tend to join civic organization. The negative sign of the estimate $(-0,552)$ is due to the fact that trust in EU institutions in the questionnaire was coded with 1 the strongest level of trust and 4 indicating a total distrust.

Interest in politics (both domestic and international politics) has a significant impact on three out of the four built models. Regional and international politics have greater influence on involvement than national topics. The reason for this may indicate that at least for young people, a broader view on politics and EU development has already started to play an important role so that their interests are not limited to domestic political events. Respondents' right-wing political orientation has a significant positive effect on their readiness to get involved in a physical conflict. Having a high 
pro-market orientation increases the likelihood for young people to vote. Actually this is one of the strongest dependencies observed in our model along with the one between mistrust in political parties and absenteeism from voting. As it would be expected, the more fashionable it is for young people to be active in politics and social activities, the more likely it is for them to participate in voluntary activities. Here the signs are negative because a smaller value indicates that this activity is more fashionable. Personal experience of discrimination is statistically significant only with regard to participation in a violent conflict and to a lesser extent with regard to participation in civic organizations. Respondents reporting to have been subject to discrimination is a small group - only $7.5 \%$ have experienced this 'rarely' and $2.1 \%$ - 'very often'. Yet it is noteworthy that youth with such experience do not turn to the ballot box and prefer to express their discontent in a direct violent conflict.

The data allow drawing the profile of the participants in each form of civic participation. The group of young people who are involved in informal voluntary activities tend to be in their teens or early twenties, in stable jobs, with a strong trust in European institutions and the media, a high interest in international politics and a firm belief that being active in civic activities is modern way of expressing their opinion. Those active in formal youth or other non-governmental organizations share high trust in political parties in Bulgaria and the country's parliament, as well as in European institutions. Youth who participate in elections are more often living in rural areas and trust local authorities more than the central government and religion organizations. As expected they trust more local political leaders and parties and place an emphasis on European values. Those who tend to get involved in violent conflicts tend to be with lower education, living in smaller towns and villages, with a strong political orientation to the right and much higher interest in Balkan than in global politics. This is also the group that more often claim to have experienced discrimination.

\section{Conclusions}

This paper addressed the question about the forms and drivers of youth participation building upon behavioral and attitudinal data about young people living in the post-communist, post-EU-accession Bulgarian society. The social context in the country 25 years after the regime change is characterized with continuing economic difficulties resulting in the postponement of youth transitions from school to work and from parental home to an independent home and family formation. Young men and women strive to achieve autonomy by devising pragmatic job search strategies and by individualizing their leisure activities. Politics in general is seen as a remote domain, reserved mainly for politicians. Given the limited resources at their disposal youth life styles are often marked by feelings of social exclusion and unwillingness to instigate social change by established institutional channels. The low political involvement is not compensated for with higher participation in formal or informal civic activities.

Our findings of the lack of representation of youth in politics are in line with the conclusions from the scare social research on youth participation in Bulgaria [41] [42]. In international comparisons Bulgarian young people stand out in the top of the countries where young people consider standing as a candidate in elections at some point in their lives [43]. While Bulgarian youth are most likely to envision participation in elections as candidates for political posts, they are the least likely to vote in parliamentary elections compared to their peers in most EU member countries (ibid). Our explanation lies in the lack of trust in the institutions that have been created in the course of the societal transformation since 1989. The low levels of trust in institutions and high dissatisfaction with how democracy is running in Bulgaria are not only an expression of the prevailing cynicism towards politics in the country. They are grounded in the particular type of social capital that helped people survive during communism and have persisted during the difficult transition to democracy and market economy. Young Bulgarians tend to concentrate their efforts in creating relations of trust and reciprocity in the closed circle of family and friends and at best are willing to provide help to people in need whom they see directly. Civic organizations are distrusted although less so than political institutions and self-organization is not widely appealing to the young in the country.

While distrust to political and civic institutions is widespread under post-communism, we could still find some significant differences in the forms and rates of participation among the groups of young people testifying to the impact of structural factors such as gender, education, family background, ethnicity, locality and socio-economic status. The established correlations suggest that some of the differences in youth participatory forms are not mere life style preferences but might be a result of social inequalities. Having higher education and middle to high socioeconomic status, creates opportunities for the young to recognize the benefits of membership in civic associations and voting. Those in more vulnerable situations are more inclined to do unpaid voluntary activities or engage in violent forms of protest. Marginalized youth tend to get involved in extreme right mobilizations [44] [45] but these are less popular among youth than ecological movements. The cause of environmental protection attracts mostly spontaneous protest actions from youth and meets with much less involvement in everyday organized activities and donations of money for nature preservation [46]. Future research should examine what meaning the young from the most privileged and the most disadvantaged groups attach to membership in civic organizations. Qualitative studies seem to be better equipped to explain young people's preferences for informal rather than formal styles of participation. When focusing on new forms of participation youth studies should not neglect voting in European, national and local elections 
because although being less popular than among adults it still remains the most common practice of youth interaction with the world of politics.

Youth in Bulgaria was constructed as the main force of social change during the National Revival in the second half of $19^{\text {th }}$ century and the communist construction in the second half of the $20^{\text {th }}$ century [1]. At present it seems to be largely forgotten together with the 'grand narratives' of the desired future. It remains to be seen how young people and democratic institutions will manage to establish an everyday regular cooperation in the field of youth policy. Our results suggest that it will be a difficult task given the prevailing lack of trust in institutions and rising social inequalities in the country.

\section{REFERENCES}

[1] S. Kovacheva, "Keys to Youth Participation in Eastern Europe," Strasbourg: Council of Europe, 2000.

[2] P. Loncle, M. Cuconato, V. Muniglia and A. Walther, "Youth Participation in Europe beyond Discourses, Practices and Realities," The Policy Press, Bristol, 2012.

[3] G. A. Almond and S. Verba, "The Civic Culture. Political Attitudes and Democracy in Five Nations," Princeton University Press, Princeton, 1963.

[4] S. Verba, N. H. Nie and J. Kim, "Participation and Political Equality: A Seven-Nation Comparison," Cambridge University Press, Cambridge, 1978.

[5] S. Finkel and E. Muller, "Rational Choice and the Dynamics of Collective Political Action: Evaluating Alternative Models with Panel Data," American Political Science Review, vol. 92, pp. 37-50, 1998.

[6] J. Teorrel, "Political participation and three theories of democracy: A research inventory and agenda," European Journal of Political Research, vol. 45, no. 5, pp. 787-810, 2006.

[7] A. Harris, J. Wyn and S. Yones, "Beyond apathetic or activist youth. 'Ordinary young people and," Young, vol. 18, no. 1, pp. 9-32, 2010

[8] P.-E. Mitev, "Bulgarian Transition and Juventisation of Society," in Transitions of Youth Citizenship in Europe: Culture, Subculture and Identity, A. Furlong and I. Guidikova, Eds., Strasbourg, Council of Europe Publishing, 2001.

[9] S.-M. Nolas, "Exploring young people's and youth workers' experiences of spaces for 'youth development': creating cultures of participation," Journal of Youth Studies, vol. 17, pp. 26-41, 2014.

[10] S. Miles, "Young People, Consumer Citizenship and Protest: The Problem with Romanticizing the Relationship to Social Change," YOUNG, vol. 23, no. 2, pp. 101-115, 2015.

[11] R. Spannring, W. Gaiser and G. Ogris, Youth and Political Participation in Europe, Opladen, Barbara Budrich Publishers, 2008.

[12] D. Blanch, "Between the traditional and the post modern: political disaffection and youth participation in Galicia," in Revisiting Youth Political participation, J. Forbig, Ed., Strasbourg, Council of Europe, 2005, pp. 61-70.

[13] K. Roberts, Youth in Transitions. Eastern Europe and the West, Palgrave Macmillan, 2009.

[14] K.-K. E., "Anti-party sentiment among young adults: evidence from fourteen West European countries," Young, vol. 17, no. 2, pp. 145-166, 2009.

[15] M. Hooghe and D. Stolle, "Youth organizations within political parties: political recruitment and the transformation of party systems," in Revisiting Youth Political participation, J. Forbig, Ed., Strasbourg, Council of Europe, 2005, pp. 43-52.

[16] P. Norris, "Young People \& Political Activism: From the Politics of Loyalties to the Politics of Choice?, report for the Council of Europe Symposium: "Young people and democratic institutions: from disillusionment to participation."," Council of Europe, Strasbourg, 2003.

[17] G. a. F. B. Odegard, "Political Participation in Late Modernity among Norwegian Youth: An Individual Choice or a Statement of Social Class?," Journal of Youth Studies, vol. 11, no. 6, pp. 593-610, 2008.

[18] D. Stolle and M. Micheletti, Political Consumerism: Global Responsibility in Action, Cambridge: Cambridge University Press, 2013.

[19] H. Vinken and I. Diepstraten, "Buy Nothing Day in Japan: Individualizing Life Courses and Forms of Engagement," Young, vol. 18, no. 1, pp. 55-76, 2010.

[20] S. Riley, Y. More and C. Griffin, "The 'pleasure citizen': Analyzing partying as a form of social and political participation," Young, vol. 18, no. 1, pp. 33-54, 2010.

[21] R. Inglehart, Modernization and Post modernization. Cultural, Economic and Political Change in 43 Societies, Princeton: Princeton University Press, 1997.

[22] C. Feixa, I. Pereira and J. J, "Global citizenship and the "New, New' social movements: Iberian connections," Young, vol. 17, no. 4, pp. 421-442, 2009.

[23] J. Juris and G. Pleyers, "Alter-Activism: Emerging Cultures of Participation among Young Global Justice Activists," Journal of Youth Studies, vol. 12, no. 1, pp. 57-75, 2009.

[24] D. Beacháin and A. P. (eds), The Colour Revolutions in the Former Soviet Republics: Successes and Failures, London, Routledge, 2010.

[25] K. Roberts, "Youth mobilisations and political generations: young activists in political change movements during and since the twentieth century," Journal of Youth Studies, vol. 18, no. 8, pp. 950-966, 2015.

[26] F. Buijs, "Muslims in the Netherlands: Social and Political Developments after 9/11," Journal of Ethnic and Migration Studies, vol. 35, no. 1, pp. 421-438, 2009.

[27] EFILWC, 2012.

[28] C. Cooper, "Imagining 'radical youth work possibilities challenging the symbolic violence within the mainstream tradition in contemporary state-led youth work practice in England," Journal of Youth Studies, vol. 15, no. 1, pp. 53-17, 2012. 
[29] R. Brooks, "Young people and political participation: An analysis of European Union policies," Sociological Research Online, vol. 14, no. 1, 2009.

[30] P.-E. Mitev and S. Kovacheva, Young People in European Bulgaria. A Sociological Portrait, Sofia: Friedrich Ebert Stiftung, 2014.

[31] S. Kovacheva, "Student Political Culture in Transition: the Case of Bulgaria," in the Puzzle of Integration. European Yearbook on Youth Policy and Research, vol. 1, CYRCE, Ed., Berlin, Walter de Gruyter, 1995, pp. 105-124.

[32] "EUROSTAT," 2014. [Online]. Available: http://ec.europa.e $\mathrm{u} /$ eurostat $/$ tgm $/$ table.do? tab $=$ table\&language $=$ en $\&$ pcode $=$ tes si190. [Accessed 13 December 2015].

[33] V. Slavtcheva-Petkova, "Towards a Sociology of the EU: The Relationship between Socio-economic Status and Ethnicity and Young People's European Knowledge, Attitudes and Identities," YOUNG, vol. 23, no. 3, pp. 222-239, 2015.

[34] N. S. Institute, "NSI," 2015. [Online]. Available: http://www.nsi.bg/bg/content/766/\%D1\%81\%D1\%82\%D0\% B0\%D1\%82\%D0\%B8\%D1\%81\%D1\%82\%D0\%B8\%D1\%8 $7 \% \mathrm{D} 0 \% \mathrm{~B} 5 \% \mathrm{D} 1 \% 81 \% \mathrm{D} 0 \% \mathrm{BA} \% \mathrm{D} 0 \% \mathrm{~B} 8-\% \mathrm{D} 0 \% \mathrm{~B} 4 \% \mathrm{D} 0 \%$ B0\%D0\%BD $\%$ D0\%BD $\%$ D0\%B8. [Accessed 13 December 2015].

[35] S. Kovacheva, "Overview of the Implementation of the EU Youth Strategy in the Field of Employment," Slovak Journal of Political Sciences, vol. 14, no. 1, pp. 5-23, 2014.

[36] K. Hurrelman and M. Weichert, Lost in Democratic Transition? Political Challenges and Perspectives for Young People in South East Europe, Berlin, Friedrich Ebert Stiftung,
2015.

[37] P.-E. Mitev, the New Young. Bulgarian Youth and the European Perspective, Sofia: East-West, 2005.

[38] F. Pichler and C. Wallace, "Patterns of Formal and Informal Social Capital in Europe," European Sociological Review, vol. 23, no. 4, pp. 423-435, 2007.

[39] "EUROFOUND," 2014. [Online]. Available: http://www.eur ofound.europa.eu/news/spotlight-on/youth/overview-youth-i ssues-a-top-priority.

[40] P. Boyadzieva, "Trust - the invisible axis of society," in European Values in Bulgarian Society, G. Fotev, Ed., 2009.

[41] A. Yosifova, the Young People and Politics, Sofia: New Bulgarian University, 2007.

[42] I. Dichev and O. S. (eds.), the New Young and the New Media, Sofia: Open Society Institute, 2009.

[43] "EUROBAROMETER," 2013. [Online]. Available: http://ec.europa.eu/public_opinion/.

[44] T. A., The Extreme Right in Bulgaria, Sofia: Freidrich Ebert Stiftung, 2013.

[45] K. Avramov, "The Bulgarian Radical Right: Marching Up from the Margins," in Transforming the Transformation? The East European Radical Right in the Political Process, M. Minkenberg, Ed., New York, Routledge, 2015, pp. 299-318.

[46] R. Stoilova, "Civic participation in environmental protection in Bulgaria," Sociological Problems, no. Special issue, pp. 50-69, 2014. 